\title{
Effect of environmental hygiene and water storage on the prevalence of malaria among pregnant women in Abeokuta, Nigeria
}

\author{
Olufunmilayo Ajoke Idowu
}

Department of Biological Sciences, Federal University of Agriculture, Abeokuta, Nigeria; tomiwo2@gmail.com

Received 11 November 2013; revised 21 December 2013; accepted 4 January 2014

Copyright (C) 2014 Olufunmilayo Ajoke Idowu. This is an open access article distributed under the Creative Commons Attribution License, which permits unrestricted use, distribution, and reproduction in any medium, provided the original work is properly cited. In accordance of the Creative Commons Attribution License all Copyrights (C) 2014 are reserved for SCIRP and the owner of the intellectual property Olufunmilayo Ajoke Idowu. All Copyright (C) 2014 are guarded by law and by SCIRP as a guardian.

\section{ABSTRACT}

The effect of availability of cultivated and/or uncultivated land, stagnant water around residential areas and the practice of water storage on the prevalence of malaria infection was assessed among four hundred and sixty-four (464) pregnant women. The prevalence of malaria infection recorded at one stage of pregnancy or the other among enrolled women in this study was $56.9 \%$. Records of infection observed among women living in areas where there were stagnant water and cultivated or uncultivated land were not statistically different from those without such environmental factors in their residence $(P>0.05)$. The practice of water storage though still a common practice among women in Abeokuta (98.9\%) was also not found to significantly influence the malaria status of the pregnant women; infection was higher among women that did not store water in their homes than those that claim to store. Storing of water was mainly in containers with cover implying that the women have a good understanding of the necessary precaution for storing water in homes; there was also no significant difference between mode of water storage and parasitaemia. The physico-chemical composition of the tap water stored may have prevented the breeding of Anopheles mosquitoes in them. We conclude that water storage in homes may not be strong risk behaviour for malaria transmission especially in areas where appropriate measures are employed for water storage in homes.

\section{KEYWORDS}

Prevalence; Parasitaemia; Pregnant;

\section{Environmental Factors; Infection}

\section{INTRODUCTION}

Malaria is a life threatening parasitic disease transmitted by mosquitoes.

Approximately $40 \%$ of the worlds' population is living in the worlds' poorest countries that are at risk of malaria. The disease was once widely spread but successfully eliminated from many countries with temperate climate during the mid 20th century [1]. Today malaria is found throughout the tropical and sub-tropical regions of the world and causes more than 300 million acute illnesses with at least one million deaths annually. Ninety percent of deaths due to malaria occur in Africa south of the Sahara [2].

In most endemic areas of the world, pregnant women are the main adult risk group for malaria [3]. The burden of malaria infection during pregnancy is caused chiefly by Plasmodium falciparum. The association of malaria and pregnancy sometimes has serious repercussion on the foetus and increases maternal morbidity leading to low birth weight (LBW-infants born with birthweight less than 2500 g) either by premature delivery or by impaired growth in utero or both $[3,4]$. The control of malaria has been a priority for the World Health Organisation (WHO) since it was founded in 1948. Various measures have been employed to curb the scourge of this disease. Some of the measures that protect against infection are directed against the mosquito vector either in larval or adult stages [1].

The main methods of controlling larvae include elimination of breeding places, e.g. by drainage and filling of ditches. Larvicides or petroleum oil can also be applied on the surfaces of stagnant water. The periodic drying of irrigation channels has also been known to be 
effective in eliminating mosquito breeding sites. Transmission of malaria is dependent on many factors such as climate, landscape, human behaviour and socio-cultural structures. Storage of water in the home and availability of uncultivated land around the house have been known to be risk factors for malaria transmission [5]. Anopheline species (malaria parasite vector) are known to breed in domestic containers [6,7]. This study is therefore aimed at assessing the effect of some environmental factors and household water storage on the prevalence of malaria among pregnant women.

\section{MATERIALS AND METHOD}

Pregnant women for this study were recruited from three antenatal care centers namely Federal Medical Centre (FMC) Idi Aba, Ogun State General Hospital (OSGH) Ijaye and Araromi traditional birth home (TBH) Iberekodo all in Abeokuta. There was a continuous enrolment of pregnant women into the study from the 3 antenatal centres for 12 months (through dry and raining seasons).

Ethical Approval: Ethical approval for the study was issued by the ethical review committee of the hospitals used for the study.

After ethical clearance was obtained, enrolment into the study was done at the time of antenatal booking (i.e. first antenatal visit).

Informed Consent: The study was first introduced to the pregnant women and informed consents were obtained from them. As many as consented were immediately enrolled into the study and given enrolment numbers with which they were monitored monthly throughout pregnancy for Malaria Parasite (MP) (through dry and raining seasons).

Parasitological Examination: Thick and thin blood films stained in Geimsa were used to assess malaria status of enrolled pregnant women.

Questionnaires were also administered to the women at the point of enrolment to gather demographic information on parity, educational qualification, level of environmental hygiene and household water storage activities.

Data Analysis: Data obtained were entered into the computer and analysed using the SPSS version 10.1 for windows. Descriptive statistics were computed for all relevant data. Associations were tested using Epi-Info 6.

\section{RESULTS}

A total of four hundred and sixty-four women (464) were enrolled in this study; $95.4 \%$ of them have formal education. The level of education ranged between primary education (31.5\%) secondary education (38.3\%) and tertiary education (25.6\%); 4.6\% were without formal education (Table 1 ). The prevalence of malaria rec- orded among the pregnant women at one stage of pregnancy or the other was 56.9\%. Questionnaires responses indicated that almost $44 \%$ of the pregnant women had uncultivated land around their residential apartment; record of infection was however higher among those with uncultivated land around their apartment (60.3\%) than those without (54.2\%) (Table 2). The difference recorded in

Table 1. Demographic characteristics of pregnant women enrolled in the study.

\begin{tabular}{|c|c|}
\hline Demographic characteristic & N (\%) \\
\hline \multicolumn{2}{|c|}{ Educational qualification } \\
\hline Primary & $146(31.5 \%)$ \\
\hline Secondary & $178(38.3 \%)$ \\
\hline Tertiary & $119(25.6 \%)$ \\
\hline Without formal education & $21(4.6 \%)$ \\
\hline \multicolumn{2}{|c|}{ Gravid status } \\
\hline Primigravidae & $137(29.5 \%)$ \\
\hline Multigravidae & $327(70.5 \%)$ \\
\hline \multicolumn{2}{|c|}{ Marital status } \\
\hline Married & $444(95.7 \%)$ \\
\hline Single & $20(4.3 \%)$ \\
\hline \multicolumn{2}{|c|}{ Age range (years) } \\
\hline $15-19$ & $26(5.6 \%)$ \\
\hline $20-24$ & $127(27.4 \%)$ \\
\hline $25-29$ & $166(35.8 \%)$ \\
\hline $30-34$ & $95(20.5 \%)$ \\
\hline $35-39$ & $45(9.7 \%)$ \\
\hline $40+$ & $5(1.1 \%)$ \\
\hline \multicolumn{2}{|c|}{ Occupation } \\
\hline Artisan & $82(17.7 \%)$ \\
\hline Civil service & $102(22.0 \%)$ \\
\hline Trading & $244(52.6 \%)$ \\
\hline Unemployed & $38(8.2 \%)$ \\
\hline
\end{tabular}

Table 2. Relationship between Malaria infection and some environmental factors around residential areas of pregnant women in Abeokuta.

\begin{tabular}{cccc}
\hline Stagnant water & $\begin{array}{c}\text { Number } \\
\text { examined }\end{array}$ & $\begin{array}{c}\text { Malaria } \\
\text { positive (\%) }\end{array}$ & $\begin{array}{c}\text { Malaria } \\
\text { negative (\%) }\end{array}$ \\
\hline Yes & 96 & $54(56.3)$ & $42(43.8)$ \\
No & 368 & $210(57.1)$ & $158(42.9)$ \\
\hline Bush & & & \\
\hline Yes & 204 & $123(60.3)$ & $81(39.8)$ \\
No & 260 & $141(54.2)$ & $119(45.8)$ \\
\hline Total & $\mathbf{4 6 4}$ & $\mathbf{2 6 4 ( 5 6 . 9 )}$ & $\mathbf{2 0 0 ( 4 3 . 1 )}$ \\
\hline
\end{tabular}


prevalence was not statistically significant $(\mathrm{P}>0.05)$ implying that this factor may not have a significant influence on the prevalence of malaria infection.

Pregnant women who claimed to have stagnant water around their apartment recorded malaria prevalence of $56.3 \%$ while those who do not have stagnant water around their apartment recorded malaria prevalence of $57.1 \%$ Table 1. Storage of water in the homes is a common practice among the enrolled women (98.9\%) though $70.3 \%$ of these women claimed to have regular tap water flow in their houses. There was a $98.2 \%$ and $100 \%$ water storage practice among those whose apartment enjoy regular tap water flow and those who do not respectively. Mode of water storage was mainly in buckets with cover (79.3\%), followed by kegs (10.3\%) then buckets without cover (6.3\%) while $4.1 \%$ store water in tanks (Table 3 ). Most of the women claim to use stored water within five days of storage. Statistic analysis shows no significant relationship between water storage and infection pattern $(\mathrm{P}>0.05)$, (Table 3). There was also no significant difference between mode of water storage and parasitaemia (Table 3).

\section{DISCUSSION}

The availability of stagnant water and uncultivated land is known to provide breeding sites for mosquitoes-the malaria vector. Environmental factors such as availability of stagnant water and uncultivated land around houses did not influence the infection pattern significantly in this study; this may be due to the ability of the women living under these conditions to prevent vector contacts adequately. Anopheles mosquitoes have also been known to have a preference for clean water $[6,8]$ and avoid polluted stagnant water.

Practice of water storage in the home could also provide breeding sites for mosquitoes, especially if such water is stored in containers without covers. The study

Table 3. Malaria infection in pregnant women and practice of water storage in the home.

\begin{tabular}{cccc}
\hline Store water & $\begin{array}{c}\text { Number } \\
\text { examined }\end{array}$ & $\begin{array}{c}\text { Malaria } \\
\text { positive (\%) }\end{array}$ & $\begin{array}{c}\text { Malaria } \\
\text { negative (\%) }\end{array}$ \\
\hline Yes & $459(98.9)$ & $261(56.9)$ & $198(43.1)$ \\
No & $5(1.1)$ & $3(60)$ & $2(40)$ \\
\hline \multicolumn{4}{c}{ Mode of storage } \\
\hline Buckets with cover & $368(79.3)$ & $213(57.9)$ & $155(42.1)$ \\
Buckets without cover & $29(6.3)$ & $16(55.2)$ & $13(44.8)$ \\
Kegs & $48(10.3)$ & $25(52.1)$ & $23(47.9)$ \\
Tanks & $19(4.1)$ & $10(52.6)$ & $9(47.4)$ \\
\hline Total & $\mathbf{4 6 4}$ & $\mathbf{2 6 4}$ & $\mathbf{2 0 0}$ \\
\hline
\end{tabular}

conducted by [6] recorded Anopheles gambiae breeding in domestic containers. In this study it was observed that the majority of the enrolled women (98.7\%) store water in their homes despite the fact that $98.2 \%$ of them claim to have regular tap water flow in their houses. The practice of water storage in the house did not influence infection pattern. This may be partly attributable to the fact that $\mathrm{pH}$, temperature and nutrient composition play important roles in Anopheles mosquito breeding [9]. These conditions may be lacking in the tap water stored by the pregnant women in this study.

Lower level of infection among those who store water could be attributed to the mode of water storage which was mainly in buckets with cover (79.3\%) and could also because such stored water was used within five days of storage not being enough for the time required for mosquitoes to breed in it $[10,11]$. This suggests that the practice of water storage may not be a strong risk practice for malaria transmission, especially among people that store water in closed containers.

\section{REFERENCES}

[1] World Health Organisation (2003) Strategic framework for malaria control during pregnancy in the WHO Africa region. WHO, Geneva.

[2] Nebe, O.J., Adeoye, G.O., Agomo, P.V. and Mosanya, M.E. (2002) A survey of perception and practices among mothers I care givers of children under five years old. The Nigeria Journal of Parasitology, 23, 69-80.

[3] Ebrahim, G.J. (1996) Malaria during pregnancy. Journal of Tropical Paediatrics, 42, 62-63. http://dx.doi.org/10.1093/tropej/42.2.62

[4] McGrgor, I.A., Wilson, M.E. and Billewicz, W.Z. (1983) Malaria infection of the placenta in the Gambia West Africa. Its incidence and relationship to still-birth weight and placental weight. Transactions of the Royal Society of Tropical Medicine and Hygiene, 77, 232-244. http://dx.doi.org/10.1016/0035-9203(83)90081-0

[5] Ukoli, F.M.A. (1991) Introduction to parasitology in tropical Africa. Textflow Limited Ibadan, 407-409.

[6] Mafiana, C.F., Anaeme, L. and Olatunde, G.O. (1998) Breeding sites of larva mosquitoes in Abeokuta, Nigeria. Nigerian Journal of Entomology, 15, 136-143.

[7] Aigbodion, F.I. and Odiachi, F.C. (2003) Breeding sites preferences of Anopheline Mosquitoes in Benin City, Nigeria. Nigerian Journal of Entomology, 20, 1-7.

[8] Aigbodion, F.I. and Anyiwe, M.A. (2005) Mosquitoes and the environments: Some economic costs of malaria in Nigeria. Nigerian Journal of Entomology, 22, 93-107.

[9] Oyewole, I.O., Momoh, O.O., Anyasor, G.N., Ogunnowo, A.A., Ibidapo, C.A., Oduola, O.A., Obansa, J.B. and Awolola, T.S. (2009) Physico-chemical characteristics of Anopheles breeding sites: Impact on fecundity and progeny development. African Journal of Environmental Science and Technology, 3, 447-452. 
[10] Lehane, M.J. (1991) Biology of blood sucking insects. Herper Collins Academic, London, 288 p. http://dx.doi.org/10.1007/978-94-011-7953-9
[11] Service, M.W. (1999) A guide to medical entomology. Macmillian Press Ltd., London, 189 p. 